\title{
ANALYSIS OF FATIGUE BEHAVIOR OF GLASS/CARBON FIBER EPOXY COMPOSITE
}

\author{
Ujjwal Makkar', Mrinalini Rana ${ }^{2}$, Amritpreet Singh ${ }^{3}$ \\ ${ }^{1}$ Assistant professor, Department of mechanical engineering, lovely Professional University, Punjab, India \\ ${ }^{2}$ Assistant professor, D.A.V Institue of Engineering and Technology, Jalandhar ,Punjab, India \\ ${ }^{3}$ Assistant professor, Department of mechanical engineering, lovely Professional University, Punjab, India
}

\begin{abstract}
There are so many applications of composite materials in the past 20 years due to strong demand in material performance set by technological developments, the use of composite materials has increased manifold. Most of these applications of the composite material are situations where the reduction in strength and durability due to fatigue process is very likely. This work has been a great need in the exact fatigue properties of glass and carbon fiber reinforced epoxy composites. In this study, both unidirectional carbon and glass fiber reinforced epoxy composites were detected for fatigue test by rotating bending machine.It was found that the probability distribution of the resistance fatigue of carbon fiber and glass fiber composite materials reinforced by fibers, at certain stress level, can be prepared by Weibull distribution of two parameter with statistical co-relation coefficient values greater than 0.80. Many methods were used to find out the parameters of the Weibull distribution. Kolmogorov-Smirnov goodness of fit was also used to amplify the results mentioned above. The Weibull distribution with two parameters is used to integrate the probability of default in the $S$ - $N$ relationship.
\end{abstract}

Keywords: Composite, Fatigue test, $S-N$ curve.

\section{INTRODUCTION}

The use of composite material is increasing day by day and the ability to predict the failure of structure is the major challenges in advance applications like aerospace and to find out the performance of these material becomes important.

In most applications, fatigue loads can not be avoided. Effective and efficient use of composite materials, which requires in-depth understanding of the fatigue life. In fiberreinforced composite body fatigue is a complex phenomenon, a lot of research is in process. The composite materials are anisotropic and heterogeneous, and the fatigue behavior is more complicated than that of homogeneous and isotropic materials such as metals. The main reasons are the different types of damage that may occur, for example, fiber breakage, matrix cracking, fiber buckling and their interactions [1]. Fatigue failure in the composite will be added from the damage caused by the significant volume of the sample instead of a single dominant cracks, which is often found in most brittle materials isotropic [2], accompanied multiplied.

Besides the differences in fatigue life of metal and composite, associated fatigue damage mechanisms showed that the fatigue process is stochastic in both the cases. To find out the fatigue strength / durability of the composite was mainly on experimental studies. Variability usually results occurs at same stress level in Strength / life, followed by same test procedures. In the past, the variability was very unimportant to the use of the large safety factor, but now these days in advance design this variability requires accurate characterization. Then, the dispersion of the fatigue life was the object of the statistical analysis by various researchers [3] [6] [7].

There are various mathematical models used to study the statistical dispersion of the fatigue life. Logarithmic-normal (lognormal) distribution function turned out to be one of the most popular models. It has been suggested that the fatigue life function $\mathrm{N}$ is considered normal distribution [4]. So the lognormal distribution has been widely used for this purpose. However, it was then observed that the function of danger or risk of log-normal distribution decreases with the increase of the duration of life [5]. For this result is in contrast with the fundamental physical phenomenon of the progressive deterioration of the technical material fatigue process.

In order to assess the reliability of the composite structures, the Weibull distribution function is useful and versatile to describe the properties of the composite material. This is due to the reason that the probability density function for the Weibull distribution has a variety of shapes. For example, if the shape parameter of the distribution is equal to 1 , it becomes exponential distribution of two parameters. To form almost three parameters, the function is able to approximate a normal distribution. Therefore physically valid assumptions, sound experimental verification, the relative ease of use and advanced statistics, proved to be the Weibull distribution in order to describe the properties of the composite materials a useful and versatile tool. 
Many previous studies on the fatigue strength / durability of polymer composites has been concerned with unidirectional laminate layers or angle ply [3] [6] [7]. Pultruded composites have various applications, such as overhead power lines, etc. In these applications, large volume of fractions glass fibers and carbon fibers are necessary to continuously a high rigidity and the composite strength. The manufacturing process with a high fiber content was only pultrusion, which is relatively seldom for other glass- fiber and carbon reinforced plastics. In previous studies on the fatigue strength / life GRP pultruded rods of life reported [8]. Fiber volume fraction ranging from $20 \%$ to $45 \%$ was used in the previous studies which were manufactured at laboratories, in which fiber content is quite less as compared to the fiber content in commercially made pultruded rods. It was suggested, conduct investigations of fatigue on various types of commercially available glass fiber and carbon fiber reinforced pultruded rods.

\section{Notations}

$\mathrm{CV}=$ Coefficient of data variation sample.

$f(n)=$ Distribution function of Probability.

$\mathrm{F}(\mathrm{n})=$ Distribution function of Cumulative.

GFREC $=$ Glass-fiber reinforced epoxy composite

CFREC $=$ Carbon-fiber reinforced epoxy composite

$i=$ Order number of the data point in the sample.

$k=$ Total number of data points in the sample.

$\mathrm{L}_{\mathrm{R}}=$ Survivorship function/survival probability/reliability function.

$\mathrm{n}=$ Number of cycles

$\mathrm{N}=$ Number of cycles to fatigue-life.

$\mathrm{P}_{\mathrm{f}}=$ Probability of failure

$r=$ coefficient of Statistical co-relation

$\mathrm{u}=$ Scale parameter of Weibull distribution

$\alpha=$ Weibull slope

$\sigma=$ Applied fatigue stress level.

$\sigma_{\mathrm{ult}}=$ Ultimate tensile strength

\section{APPROACH OF THE EXPERIMENT}

\subsection{Materials used for Study}

In the analysis, the standard glass fiber reinforced composites (GFREC) and carbon fiber reinforced composite (CFREC) in the form of pultruded rods were produced using die and reinforcing materials such as epoxy.

\subsection{Detail of the Specimen}

On a lathe, pultruded rods of glass-fiber reinforced and carbon fiber reinforced were cut to the size of necessary dimensions. To carry fatigue tests, pultruded rod is machined to the required size of the sample, as shown in Fig. 1 of a CNC lathe. Some other researchers have also followed a similar pattern of their research $[8,12]$ used.

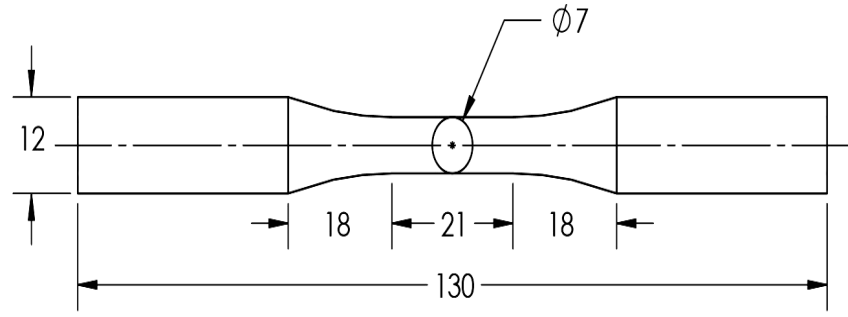

Fig 1 Specimen Dimensions used for study in $\mathrm{mm}$

\subsection{Detail of Fatigue Tests}

All fatigue tests were carried out on a machine rotary bending type fatigue test, the cantilever loading samples. This machine has a chuck mounted on the main shaft for holding the sample at one end, while the other end of the sample supported in plain bearings. Load have been used for the final sample with the dead weight as shown in Fig.3.The main spindle driven by an electric motor running at $1440 \mathrm{rpm}(25 \mathrm{~Hz})$. Table 1 represented the tensile strength values (бult) for GFREC and CFREC with fatigue stress tests. Fig; 2 represents the experimental setup. The fatigue tests were carried out in two different levels of stress $\sigma=$ $341 \mathrm{MPa}, \sigma=395 \mathrm{MPa}$, which are in the range of 50 to $75 \%$ of the maximum stress (from $\sigma_{\mathrm{ult}}$ ) for both materials studied.

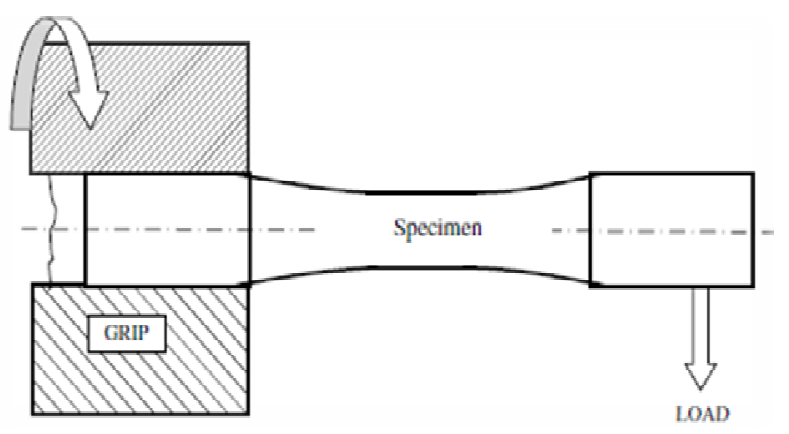

Fig 2 Schematic setup of fatigue testing.

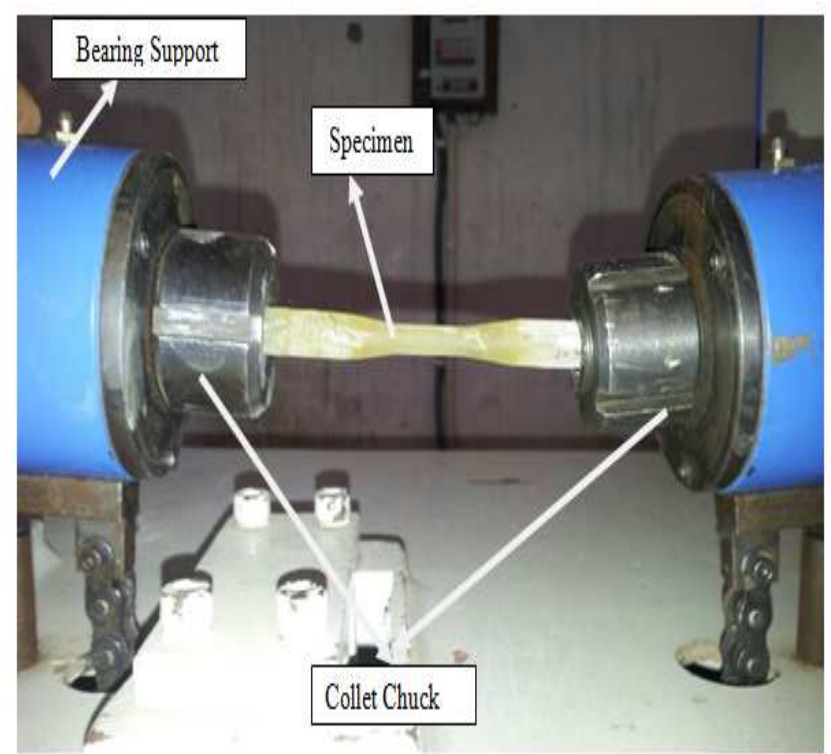

Fig 3 Fatigue testing setup view 
Table 1: Ultimate tensile strength \& fatigue test levels for GFREC and CFREC

\begin{tabular}{|c|c|c|}
\hline Material & GFREC & CFREC \\
\hline $\begin{array}{ll}\text { Ultimate } & \text { tensile } \\
\text { strength }\left(\sigma_{\mathrm{ut}}\right) & \end{array}$ & $571 \mathrm{MPa}$ & $600 \mathrm{MPa}$ \\
\hline Fatigue test parameters: & $341 \mathrm{MPa}(60 \%)$ & $341 \mathrm{MPa}(57 \%)$ \\
\hline $\begin{array}{lll}\text { Fatigue } & \text { stress- } & \mathrm{MPa} \\
\left(\%\left(\sigma_{\mathrm{ut}}\right)\right) & & \end{array}$ & $395 \mathrm{MPa}(70 \%)$ & $395 \mathrm{MPa}(66 \%)$ \\
\hline
\end{tabular}

\section{FAILURE MODE}

The failure mode of GFREC and CFREC samples in rotating bending test is discussed for the test at stress levels of 60 to $70 \%$ of the Ultimate tensile strength $\left(\sigma_{\mathrm{ut}}\right)$.

In this observation, axial cracks occurred in the direction parallel to the fibers in the sample medium. Axial cracks in the sample observed speeding throughout the length of the sample. There was no increment in the length of parallel portion, as the axial slots in the matrix are being spread. It is noted that the sample failed due to a catastrophic failure of the fibers. De-bonding, the separation matrix and axial cracks are observed. In the observations, there were no pullout of the fiber at higher stress levels in GFREC, but some pullout of the fiber is noted at certain sites CFREC, as shown in Figure 4 and Figure 5.

Similar damage model has already been reported by some researcher for glass fiber [12]

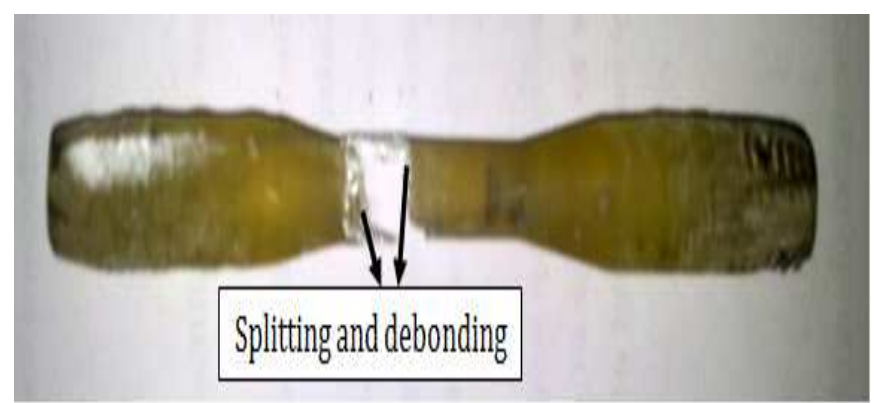

Fig 4 Failed GFREC Specimens

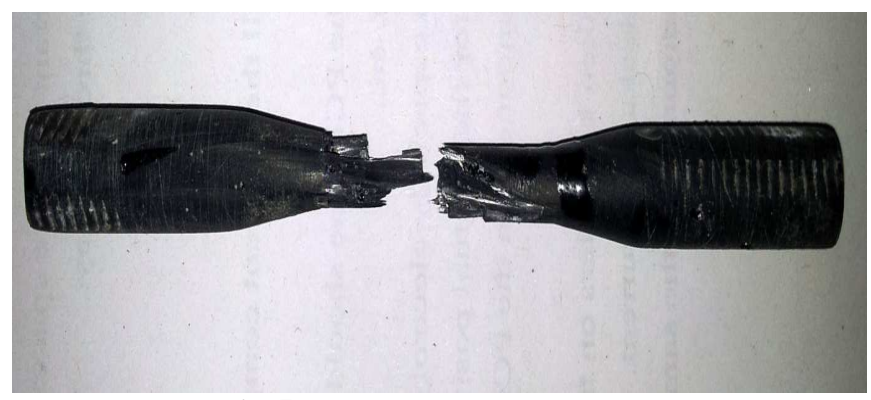

Fig 5 Failed CFREC Specimen

\section{DISCUSSION AND ANALYSIS}

The whole fatigue-life data obtained at certain stress levels for above said test materials, i.e., GFREC \& CFREC is listed in ascending order in Table 2 and Table 3, respectively.
Table 2: Experimental fatigue life data for GFREC

\begin{tabular}{|l|l|}
\hline \multicolumn{2}{|l|}{ Stress levels ' $\sigma$ ' } \\
\hline $341 \mathrm{MPa}(60 \%)$ & $395 \mathrm{MPa}(70 \%)$ \\
\hline 8813 & 5180 \\
9092 & 5230 \\
10532 & 5290 \\
11240 & 5410 \\
11835 & 5535 \\
12131 & 5590 \\
\hline
\end{tabular}

Table 3: Experimental fatigue life data for CFREC

\begin{tabular}{|l|l|}
\hline \multicolumn{2}{|l|}{ Stress levels ' $\sigma$ ' } \\
\hline $341 \mathrm{MPa}(57 \%)$ & $395 \mathrm{MPa}(66 \%)$ \\
\hline 15145 & 7387 \\
15836 & 7935 \\
15987 & 8244 \\
16423 & 8367 \\
17109 & 8826 \\
17340 & 8895 \\
\hline
\end{tabular}

\subsection{Fatigue-Life Data Statistical Analysis}

Probability density function (PDF), $\mathrm{f}(\mathrm{n})$ and cumulative distribution function (CDF) $\mathrm{F}(\mathrm{n})$, were used as two parameters of Weibull distribution to evaluate fatigue strength, as follows:

$$
\begin{aligned}
& f(n)=\frac{\alpha}{u}\left(\frac{\mathrm{n}}{\mathrm{u}}\right) \exp \left[-\left(\frac{n}{u}\right)\right] \\
& F(n)=1-\exp \left[-\left(\frac{n}{\mathrm{u}}\right)^{\alpha}\right]
\end{aligned}
$$

“ in which $\mathrm{n}=$ specific value of the random variable $\mathrm{N} ; \alpha=$ shape parameter or Weibull slope at stress level $\sigma$ and $\mathrm{u}=$ scale parameter or characteristic life at stress level $\sigma$ "[12]. Certain methods, such as the graphical method, moment method, the method of maximum likelihood for the parameters $\alpha$ and $U$ are known. In this review, the statistical distribution of fatigue-life of glass-fiber and carbon-fiber reinforced pultruded composites the graphical method is used at a various stress level $\sigma$ follows the two-parameter Wei-bull distribution, graphical method is employed to obtain Wei-bull parameter.

\subsection{Graphical Method Analysis of Fatigue Life Data}

The reliability function or probability of survival, $L_{R}(n)$, may be defined as $\mathrm{L}_{\mathrm{R}}(\mathrm{n})=1-F(n)$, and substituting this value of $F(n)$ in Eq. (2) it is rewritten as :

$$
L_{R}(\mathrm{n})=\exp \left[-\left(\frac{\mathrm{n}}{\mathrm{u}}\right)^{\alpha}\right]
$$


By taking logarithm twice on both sides of Eq. (3), it can be modified as

$$
\ln \left[\ln \left(\frac{1}{L_{R}}\right)\right]=a \ln (n)-a \ln (u)
$$

Eq. (4) Shows a linear relationship between $\ln \left[\ln \left(1 / \mathrm{L}_{\mathrm{R}}\right)\right]$ and $\ln (n)$. To obtain graph from Eq. (4), the data of the fatigue strength initially arranged according to a certain stress level in ascending order of cycles to failure and the survival function for each data $L_{R}$ is given by following relationship [9];

$$
L_{R}=1-\frac{i-0.3}{k+0.4}
$$

"where $\mathrm{i}$ denotes the failure order number and $\mathrm{k}$ represents the number of data points in a data sample under consideration at a particular stress level $\sigma$. The empirical survivorship function in the form of $\ln \left[\ln \left(1 / \mathrm{L}_{R}\right)\right]$ for each fatigue-life data is then plotted on a graph with the corresponding fatigue lives $\ln (\mathrm{N})$. If a linear trend is established for the data points, the best fit line is drawn using method of least squares. It can then be assumed that fatigue-life data for that particular stress level follows the two-parameter Weibull distribution. The slope of the line provides an estimate of shape parameter $\alpha$ and the characteristic life u can be obtained"[12]. Following are the observation and calculation for Glass-Fiber Reinforced epoxy composite (GFREC) at stress level $341 \mathrm{Mpa}$.

One typical graph for fatigue-life data at stress level $\sigma=341$ MPa for GFREC is shown in Fig. 6. The approximate straight line plot in Fig. 6 with statistical correlation coefficient $r$ of 0.80 indicates that the two-parameter Weibull distribution is a reasonable assumption for the statistical distribution of fatigue-life at this stress level. Similar trends are observed GFREC at 395MPa and for CFREC at $341 \mathrm{MPa}$ and $395 \mathrm{MPa}$. Table 4 and Table 5 represents various observations results.

Table 4: Weibull parameters Values for fatigue-life of GFREC

\begin{tabular}{|l|l|l|}
\hline Graphical Method & $\alpha$ & $\mathrm{u}$ \\
\hline$\sigma=341 \mathrm{MPa}$ & 7.582 & 11241.35042 \\
& & 5451.943705 \\
\hline$\sigma=395 \mathrm{MPa}$ & 32.37 & \\
\hline
\end{tabular}

Table 5: Weibull parameters Values for fatigue-life of CFREC

\begin{tabular}{|l|l|l|}
\hline $\begin{array}{l}\text { Graphical } \\
\text { Method }\end{array}$ & $\alpha$ & $\mathrm{u}$ \\
\hline$\sigma=341 \mathrm{MPa}$ & 20.54 & 16688.79303 \\
\hline$\sigma=395 \mathrm{MPa}$ & 15.1 & 8487.566576 \\
\hline
\end{tabular}

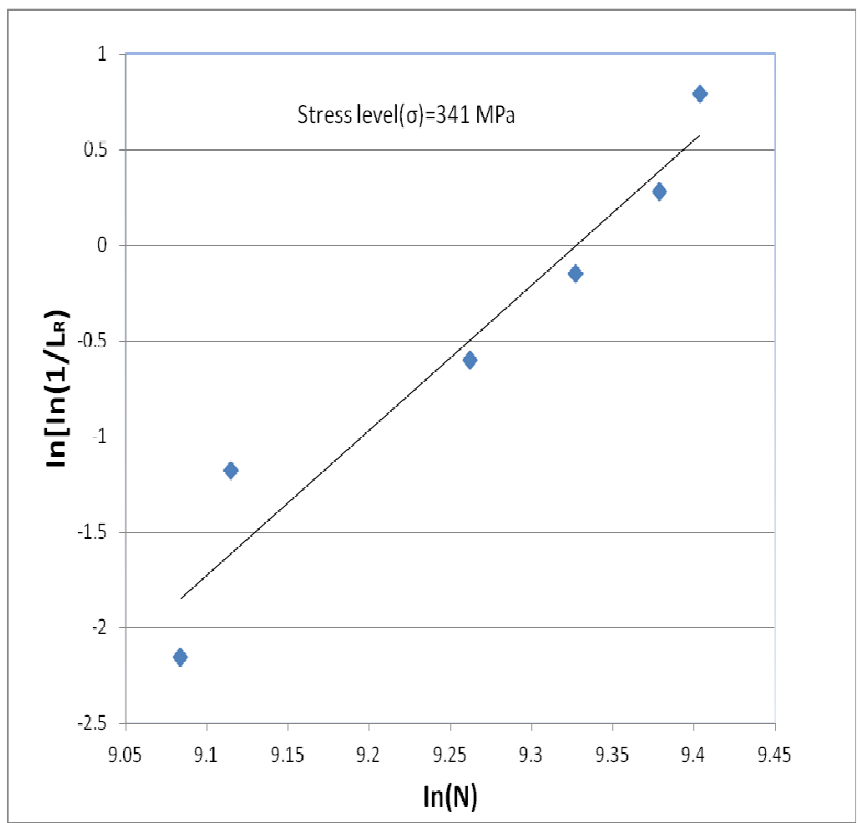

Fig 6 Graphical analysis of fatigue life data for GFREC

\subsection{Kolmogorov-Smirnov Test For Goodness-Of-} Fit

In the analysis section, by graphical method two parameter of weibull distributions was used at different stress level to show the statistical distribution of fatigue life for glass fiber and carbon fiber reinforced composite material. Kolmogorov-Smirnov test [9] with the following equation can be used to confirm that the result:

$$
D_{i}=\max _{i=1}^{k}\left[\left|F^{*}\left(x_{i}\right)-F\left(x_{i}\right)\right|\right]
$$

where $\mathrm{F} *\left(\mathrm{x}_{\mathrm{i}}\right)=\mathrm{i} / \mathrm{k}=$ cumulative histogram, $\mathrm{i}=$ ordinal number of data points, $\mathrm{k}=$ the total number of data points in the sample were considered at a given stress level and $\mathrm{F}\left(\mathrm{x}_{\mathrm{i}}\right)$ $=$ the cumulative distribution hypothesis Eq. (2). Kolmogorov-Smirnov Table [9] was used to obtain the value of $D_{c}$ and is compared with $D_{i}$ values. If $D_{i}<D_{c}$ This model can be accepted with a 5\% significance level. For all stress levels tests GFREC and CFREC fatigue life data is

\begin{tabular}{|c|c|c|c|}
\hline Stress level & $\overline{D_{i}}$ & $\mathrm{D}_{\mathrm{C}}$ & Remarks \\
\hline \multicolumn{4}{|c|}{ Material-GFREC } \\
\hline$\sigma=341 \mathrm{MPa}$ & 0.168377 & 0.521 & Accepted \\
\hline$\sigma=395 \mathrm{MPa}$ & 0.188861 & 0.521 & Accepted \\
\hline \multicolumn{4}{|c|}{ Material-CFREC } \\
\hline$\sigma=341 \mathrm{MPa}$ & 0.161149 & 0.521 & Accepted \\
\hline$\sigma=395 \mathrm{MPa}$ & 0.131374 & 0.521 & Accepted \\
\hline
\end{tabular}
used. The results are summarized in Table 6.

Table 6: Results of Goodness of fit test 


\subsection{Failure Probability and S-N Relationships}

Previous researchers $\mathrm{S}-\mathrm{N}$ relationship did not report the failure probability $\mathrm{P}_{\mathrm{f}}$ to integrate an important parameter in the study of fatigue. Weibull distribution is here that the combination of the probability of failure of the relationship of the S-N GFREC and CFREC. Substituting $1-\mathrm{P}_{\mathrm{f}}=\mathrm{L}_{\mathrm{R}}$ in the equation. (4) we obtain the following relationship:

$$
\operatorname{In}\left[\operatorname{In}\left(\frac{1}{1-P_{f}}\right)\right]=\alpha \operatorname{In}(\mathrm{n})-\alpha \operatorname{In}(\mathrm{u})
$$

rearranging

$$
\mathrm{n}=\operatorname{In}^{-1}\left[\frac{\operatorname{In}\left\{\operatorname{In}\left(\frac{1}{1-P_{n}}\right)+\mathrm{a} \operatorname{In}(\mathrm{u})\right.}{\mathrm{s}}\right]
$$

Thus, By using the weibull distribution parameter at any stress level value for fatigue life (as shown in Tables 4 \& 5 ), different failure probabilities at a given amount of stress level has been determined by using $\operatorname{Eq}(8)$. To obtain $\mathrm{P}_{\mathrm{f}}-\mathrm{S}-$ $\mathrm{N}$ diagrams, various fatigue lives values were calculated for GFREC \& CFREC for failure probabilities of $\mathrm{P}_{\mathrm{f}}=0.2,0.3$, $0.5,0.8 \& 0.95$, and are represented in Fig 7 and Fig: 8 respectively.

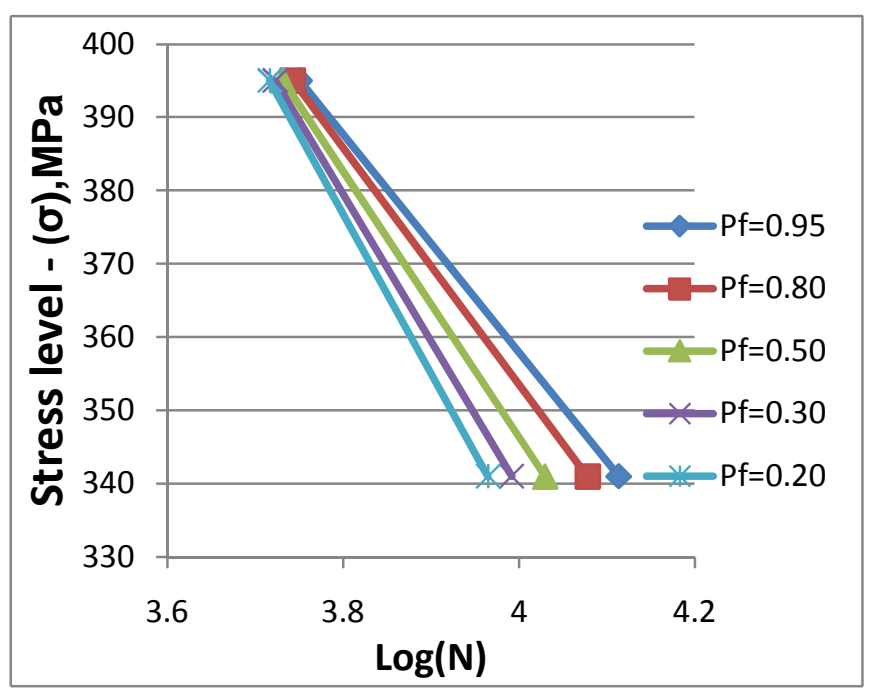

Fig. 7 Diagram for GFREC $\left(\mathrm{P}_{\mathrm{f}}-\mathrm{S}-\mathrm{N}\right)$

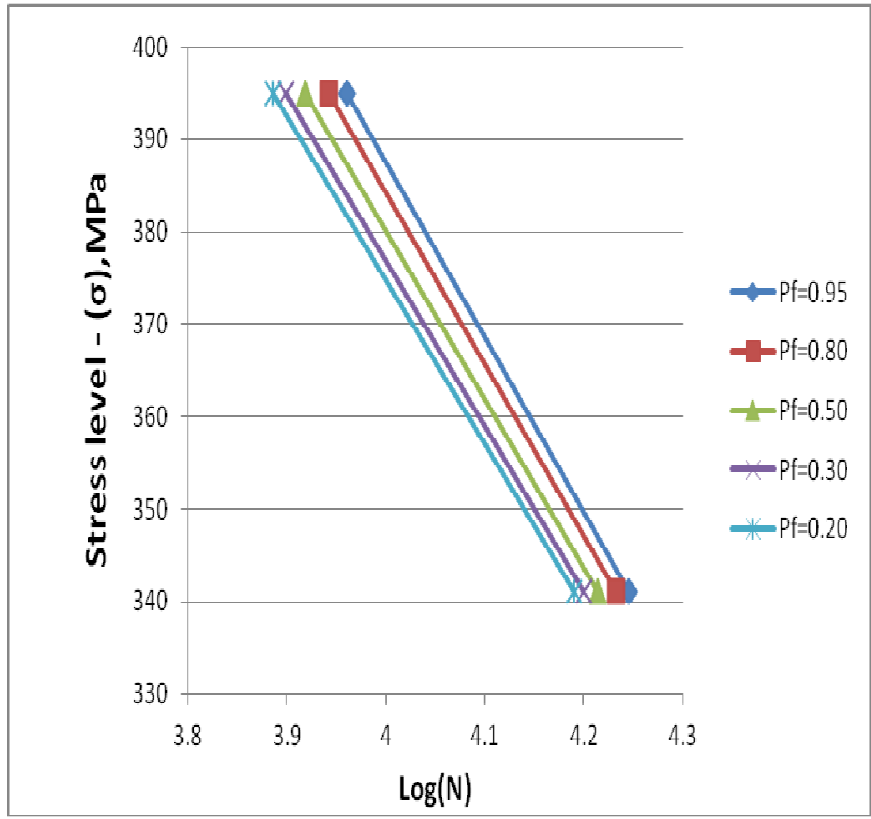

Fig. 8 Diagram for CFREC $\left(\mathrm{P}_{\mathrm{f}}-\mathrm{S}-\mathrm{N}\right)$

\section{CONCLUSION}

The conclusions drawn from this study as follows:

- During the formation of different fracture mechanism other failure mode were found at given stress level for both the material used for the study.

- Probability distribution of the fatigue life of glass fiber Rein forced epoxy composite (GFREC) and carbon fiber reinforced epoxy composite (CFREC) pultruded at each level of stress can be approximately modeled by two parameters Weibull distribution with a statistical correlation coefficient greater than 0.85 values.

- Material shows less scatter in the fatigue life data at higher stress level.

- Carbon -fiber reinforced epoxy composite (CFREC) shows more strength on $\mathrm{S}-\mathrm{N}$ curve as compare to Glass- fiber reinforced epoxy composite (GFREC).

- With two-parameter Weibull distribution $\mathrm{P}_{\mathrm{f}}-\mathrm{S}-\mathrm{N}$ parties to fiberglass and carbon fiber reinforced epoxy resin composites were produced that involves the probability of failure in $\mathrm{S}-\mathrm{N}$ relationship. This relationship can be used by designers to get the fatigue strength of GFREC and CFREC to the desired level of probability.

\section{ACKNOWLEDGEMENTS}

The authors thank the Department of Mechanical Engineering, LPU, Phagwara to provide excellent laboratory facilities that allow this work possible.

\section{REFERENCES}

[1]. Joris D, Paepegam WV. Fatigue damage modeling of fiber reinforced composite materials - review. Appl Mech Rev 2001;54(4):279-300.

[2]. Tsai SW. Composite design, 4th ed. Think Composites; 1988. 
[3]. Lee J, Harris B, Almond DP, Hammett F. Fibre composite fatigue life determination. Composites A 1997;28:5-15.

[4]. ASTM Special Publication 91-A, A guide for fatigue testing and the statistical analysis of fatigue data. ASTM $1963 ; 83$.

[5]. Gumble EJ. Parameters in the distribution of fatigue life. J Eng Mech, ASCE 1963:45-63.

[6]. Philippidis TP, Vassilopoulos AP. Fatigue design allowable for GRP laminates based on stiffness degradation measurements. Comp Sci Tech 2000;60:2819-28.

[7]. Tai NH, Ma CCM, Wu SH. Fatigue behaviour of carbon fiber/PEEK laminate composites. Composites 1995;26:5519.

[8]. Khashaba UA. Fatigue and reliability analysis of unidirectional GFRP composites under rotating bending loads. J Comp Mater 2003;37:317-30.

[9]. Kennedy JB, Neville AM. Basic statistical methods for engineers and scientists. A Dun-Donnelley Publishers; 1986. 613.

[10]. Singh SP, Kaushik SK. Flexural fatigue life distributions and failure probability of steel fibrous concrete. ACI Mater J 2000;97-M74:658-67.

[11]. Wirsching PH, Yao JTP. Statistical methods in structural fatigue. J Struct Div Proc ASCE 1970:1201-19.

[12]. Raman Bedi , Rakesh Chandra. Fatigue-life distributions and failure probability for glass-fiber reinforced polymeric composites, 2008 